\title{
ArcheoSciences
}

Revue d'archéométrie

33 (suppl.) | 2009

Mémoire du sol, espace des hommes

\section{The application of GPR Overlay analysis in archaeological prospection: Discovery at the Japanese Imperial Family tombs in Miyazaki Prefecture}

Dean Goodman, Hongo Hiromichi, Noriaki Higashi, Yasushi Nishimura, Masashi Tokuda and Hyun dok Oh

\section{OpenEdition}

\section{Journals}

Electronic version

URL: https://journals.openedition.org/archeosciences/1731

DOI: 10.4000/archeosciences. 1731

ISBN: 978-2-7535-1599-4

ISSN: 2104-3728

\section{Publisher}

Presses universitaires de Rennes

\section{Printed version}

Date of publication: 30 October 2009

Number of pages: 295-297

ISBN: 978-2-7535-0943-6

ISSN: 1960-1360

\section{Electronic reference}

Dean Goodman, Hongo Hiromichi, Noriaki Higashi, Yasushi Nishimura, Masashi Tokuda and Hyun dok Oh, "The application of GPR Overlay analysis in archaeological prospection: Discovery at the Japanese Imperial Family tombs in Miyazaki Prefecture", ArcheoSciences [Online], 33 (suppl.) | 2009, Online since 30 October 2011, connection on 01 February 2022. URL: http://journals.openedition.org/ archeosciences/1731; DOI: https://doi.org/10.4000/archeosciences.1731 


\title{
The application of GPR Overlay analysis in archaeological prospection: Discovery at the Japanese Imperial Family tombs in Miyazaki Prefecture
}

\author{
Dean Goodman *, Hongo Hiromichi*, Noriaki Higashi*, \\ Yasushi Nishimura ${ }^{* *}$, Masashi ToKudA ${ }^{* * *}$ and Hyun DoK $\mathrm{OH}^{* * * *}$
}

Key words: GPR, Overlay analysis, Relative-strongest-reflectors, Kofun, Imperial Tombs.

A method introduced over a decade ago to synthesize important GPR reflections from overlay analysis is applied to the study of Imperial Family Tombs in Japan (Goodman, 2006). In overlay analysis, individual time slice levels are independently weighted, colorized, and then overlays of the relative-strongest-reflectors are synthesized into a single $2 \mathrm{D}$ map, containing all the relevant reflector levels desired by the interpreter. The overlay of the relative-strongest-reflector can be more simply stated that the strongest pixel in color trumps the weaker pixels from the collection of time slices used in the overlay. The analysis is applied in the discovery of destroyed structures at the Japanese Imperial Family Tombs in Miyazaki prefecture, and to recently collect important reflections from within Indian pithouses at the Biesterfelt site in North Dakota. The successful discoveries at these sites, and many other, dictates the need for interpreters to interact with their data in combining information from different levels, as examination of simple separated 2D time slices, or even $3 \mathrm{D}$ images of isosurface are often not sufficient to solve subsurface imaging problems. The key elements in overlay analysis (Goodman et al., 2009, 2006) are:

1) Generating time slices of amplitude energy (not pulse amplitude).

2) Choosing a range or individual time slices where pertinent information is contained.

3) Weighting each individual time slice with a unique color transforms.

4) Overlaying the relative-strongest-reflector normalized from each time slice level.

Time slices of GPR reflections are normally taken over a time window of a microwave pulse length or larger. Thinner time slices can also be used in overlay analysis; however, in this instance the Hilbert Transform of the pulse radargrams is required before using these data. The second ingredient in overlay analysis, a range of pertinent time slices is used. Often shallower time slices can be removed from the mix in overlay analysis since unwanted surface reflections may

* Geophysical Archaeometry Laboratory, US, dean@gpr-survey.com.

** Saitobaru Archaeological Museum, Miyazaki, Japan.

*** Japanese Imperial Family Archaeological Department, Tokyo, Japan.

**** Korean National Research Institute of Cultural Properties, Daejon, Korea. 
hide deeper reflection. In addition, lower level data can be discarded in the analysis, as well as intermediate levels which do not have useful slice information. The analysis is completely flexible and non-consecutive levels, and any number of individual slices can be chosen in the analysis. The third element is the individualized weighting of reflections from each map. Each depth slice is normalized with its own unique colorization following the data histogram. Using any multiple of the standard deviation to set hi and lo cut (de-spiking) thresholds, as well as applying unique shapes over the reflection histogram, the maps are independently colorized. Auto-gaining of the time slice grids, rather than the actual radargram pulses, is where color balancing of each level is made independently. The final step in the analysis is too graphically overlay these independently colorized and transform weighted time slice maps. The method can be likened to the "strongest pixels wins" over previously plotted pixels as the depth slices are overlaid. The analysis can be displayed in the form of an animation in which progressive overlays of the relative-strongest-reflectors are mapped.

Application of overlay analysis was applied in the discovery of destroyed structures of the largest burials on the island of Kyushu. Osaho and Mesaho burial mounds were designated important burials and they became part of the Imperial Family Tombs in 1895 (Fig. 1). Folklore historical records (reference) indicate that Osaho and Mesaho are believed to be the burials of the grandparents of the first emperor of Japan, although no written documents from the time of the entombments on these mounds survives. The mounds are over 200 meters in length and 20 meters tall and are located in a protected burial mound park in Saitobaru National Burial Mounds in Miyazaki Prefecture. Mesaho mound has undergone little change in over 1500 years since it constructions

The Osaho mound however, has had some reconstruction or alteration on the bottom part of the mound. Examination of the topographic map of the site shows a long protruding bottom. The western flank corner of the shell bottom appears not to be present, making the triangular bottom somewhat asymmetrical. Archaeologists on the site believe that portions of the western flank must have been altered sometime in the past. Some historical records suggest that archery practice in the Edo period which was commonly done adjacent to large burials, may have led ancient trainees to remove material from part of the mound to build the long protruding topographic ridge like structure from the bottom of the mound.

The purpose of the GPR survey was to see if it could help in reconstruction the ancient moat and tomb bottom that once surrounded Osaho Kofun Period. The hope would be that GPR could illuminate some soil features that might indicate the original shape of the tomb bottom, indicating either a long or short triangular bottom (Fig. 2). This survey would be the first ever geophysical survey of any kind that

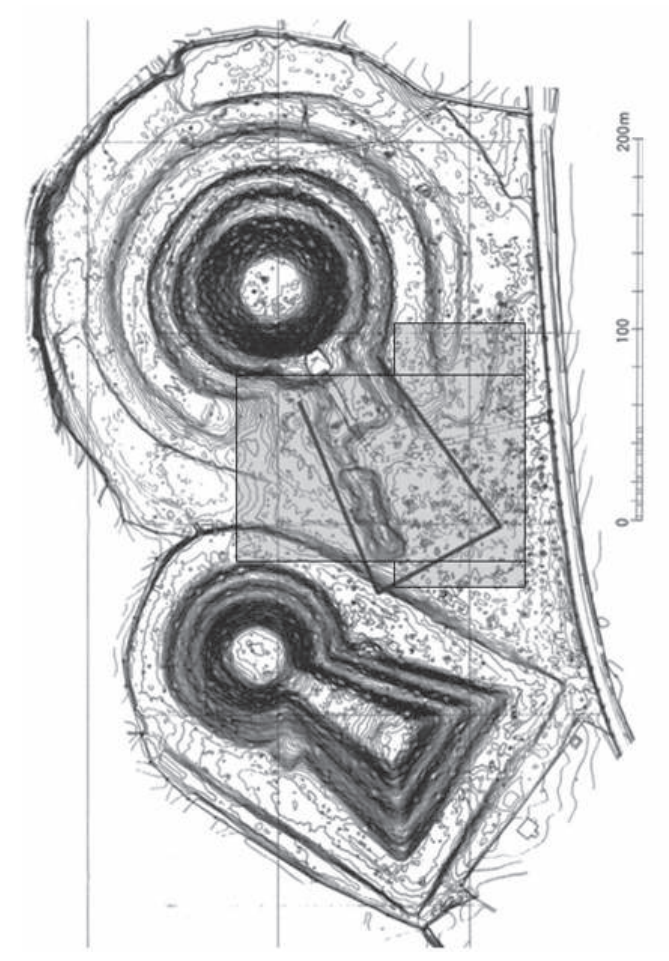

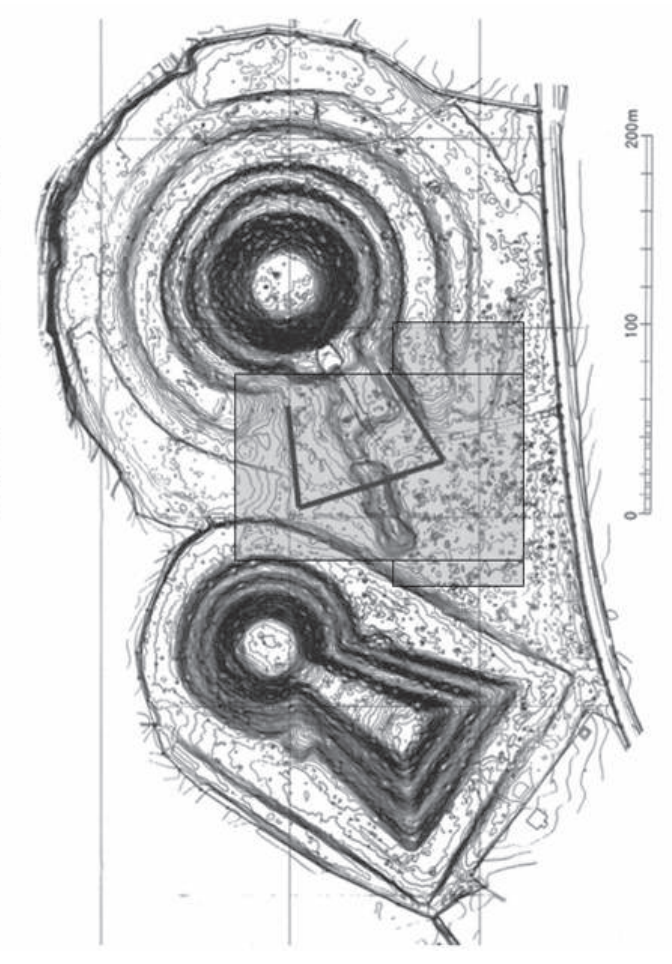

Figure 1: Location of the field surveys across the bottom portion of the Osaho mound. Two possible candidate shapes for the triangular keyhole bottom are proposed. 


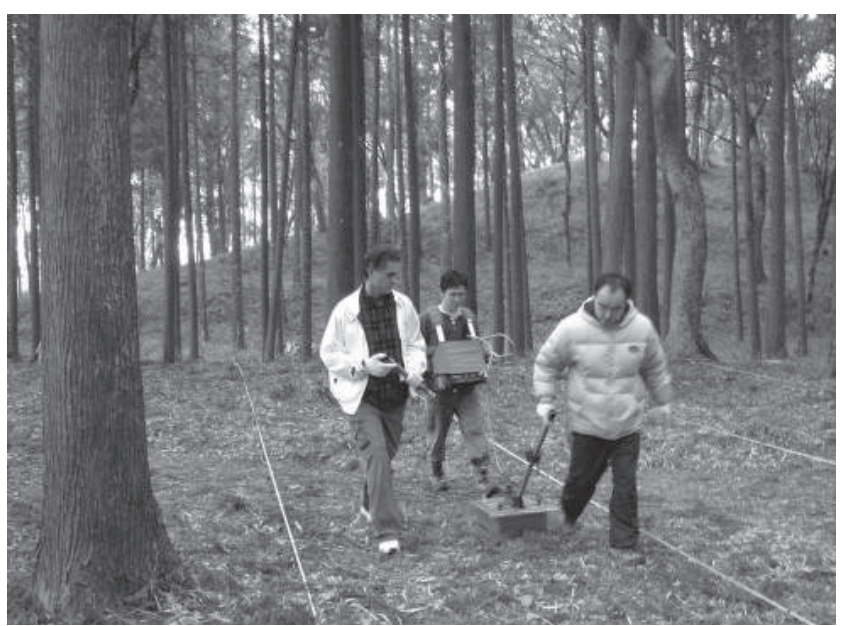

Figure 2: GPR surveying with a $500 \mathrm{MHz}$ antenna at the OsahoMesaho Kofun mounds.

would be authorized for investigating any Japanese Imperial Family cultural property. The survey was broken up into 3 field seasons from 2004-2006 and involved acquiring GPR data with both a $500 \mathrm{MHz}$ antenna as well as a lower frequency $200 \mathrm{MHz}$ antenna across the site. The individual depth slices did not contain any reflection features that could show anything close to a triangular shape. The final image that solved the subsurface secret was generated from overlay analysis in which the $500 \mathrm{MHz}$ and $200 \mathrm{MHz}$ data were used, and included overlaying all the relative-strongestreflections generated between $80-360 \mathrm{~cm}$ below the ground surface that existed on 135 individual time slice maps. The top surface data was eliminated from the mix of the final images since this data contained many surface and shallow information which shadowed the deeper reflection information. It is clear from the analysis (Fig. 3) that a triangular shaped bottom for the Osaho mound is discovered and that subsurface remnant soil structures must be responsible for the recorded image. The protruding ridge jutting out from the interpreted (GPR) boundary is probably a more recent feature that was not originally built onto the mound. Archaeologists interpreting the results believe that the mound was a scallop (short keyhole) shaped mound based on the synthesized GPR subsurface images generated from overlay analysis for the site.

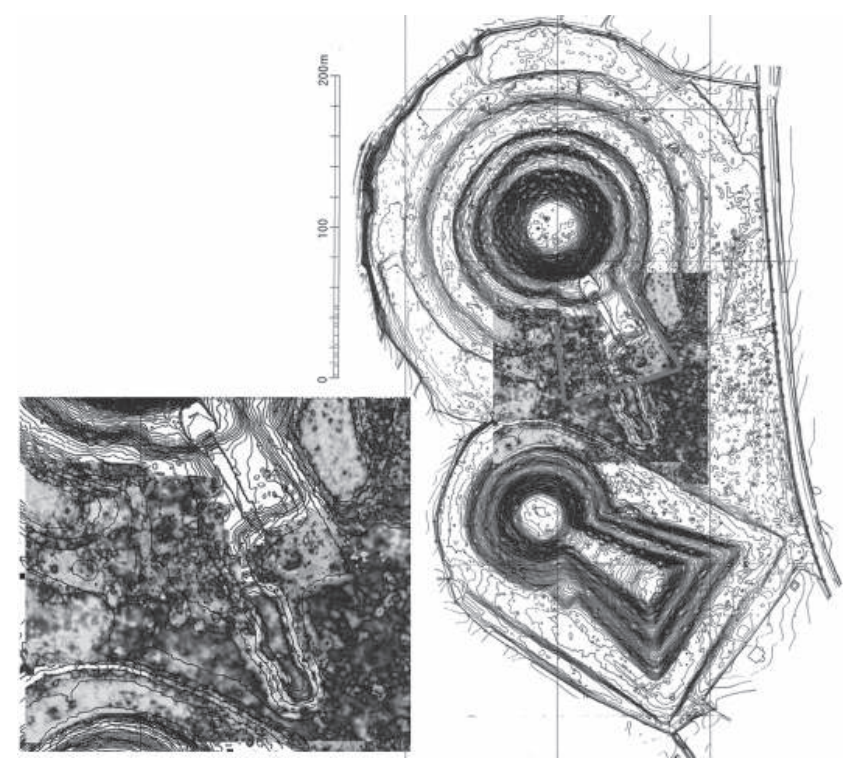

Figure 3 (see color plate): In this diagram the results from GPR surveying with the $500 \mathrm{MHz}$ and $200 \mathrm{MHz}$ data are synthesized into an overlay time slice of all relative strongest reflections recorded from $80-360 \mathrm{~cm}$. The yellow correspond to relatively strong reflections and the light gray to relatively the weakest reflections recorded. The image with interpretation of the GPR record indicates that a triangular shaped bottom can still be detected from remnant soil conditions present beneath the Osaho mound. This interpretation debunks earlier beliefs that the protruding portion of the mound bottom is probably not original construction, but occurred after the initial construction during the Kofun period.

\section{References}

Goodman, D, Piro, S., Schneider, K., Nishimura, Y., Hongo, H., Higashi, N., Steinberg, J. and Damiata, B., 2009. GPR Archaeometry. In Jol, H. (dir.), GPR Theory and Applications, Elsevier, 479-508.

Goodman, D., Steinberg, J., Damiata, B., Nishimura, Y., Hongo, H., Higashi, N. and Schneider, K., 2006. GPR Overlay Analysis for Archaeological Prospection, Proceedings of International Conference on Ground Penetrating Radar, Ohio State University. 